\title{
Health workers' strikes: a further rejoinder
}

\author{
Seymour M Glick Ben Gurion University of the Negev Faculty of Health Sciences, Beer-Sheba, Israel
}

In response to the editor's invitation to reply briefly to Brecher, I will attempt to highlight my major points.

1. All strikes represent the use of force to settle disputes and therefore raise ethical dilemmas. They resemble duels, which have gone out of fashion in civilised circles as a means of resolving disagreements between individuals, and wars, which unfortunately are still extant as a means of settling international disputes. From an ethical point of view strikes do not assure justice; on the contrary they reward the strong. 'Strong' unions, with the most ability to disrupt society by striking, may win benefits denied to 'weak' unions, which may be more deserving. Like wars, strikes may be justified if there exist grievous wrongs for which no other redress is available. Hopefully as societies progress, one could find mutually acceptable judicial or arbitration processes to settle labour disputes, just as disagreements between individuals are now usually taken to court. I believe this to be a worthwhile goal, but this goal is unattainable as long as alternatives to strikes are rejected in principle, as long as the right to strike is regarded as hallowed and inalienable, as a sacred cow which may not even be criticised.

2. Strikes in the public sector and against certain large corporations raise other ethical issues. They often do not harm those responsible for the policies against which the strikers react, but rather inflict damage on third parties, usually innocent of the decision-making role. Only in the most tangential way, and by the most convoluted logic, can the airline passenger who misses the funeral of a loved one or the patient whose operation is cancelled because of a strike be considered to bear significant responsibility for the working conditions of the pilot or nurse. Yet they are adversely affected much more so than the president of the airline or the director of the hospital. I believe there is a serious ethical question about the propriety of strikes which affect almost exclusively third parties. Again I do not claim that such strikes should never take place, but that the ethical questions should be faced honestly. Thus far most discussions of strikes have totally avoided this issue.

\section{Key words}

Strikes; health workers' strikes.
3. Health workers, and particularly physicians, are in a special class because they deal with human lives ? and because, upon joining the profession or accepting their job, they have voluntarily undertaken a

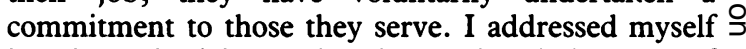
largely to physicians rather than to the whole gamut of health workers, not out of arrogance or ignorance but rather on the contrary. I did not presume to speak for the ambulance driver or orderly whose economic situation and degree of exploitation are so different from mine that it might be unfair for me to preach to them. I preferred to speak about my own profession which I do know well. All physicians' strikes on record in several continents (and I have had personal experience with several strikes) have taken place almost exclusively for the benefit of the physicians and not for the patients (in some cases demands for improvement in patient care were publicised but they were invariably secondary in nature and more often were used to provide an improved public image for the strikers and some balm to their conscience). In none of the strikes of which I am aware have the physicians been in such dire straits as to justify endangering patients' lives or causing them to suffer.

I do believe physicians are different, not because $\delta$ they deserve any privileges, but because they have greater responsibility as leaders in society. Brecher's 윽 claim notwithstanding I did cite scholarly and well- $D$ reasoned presentations by Kass (1) and by Pellegrino (2) to support my contention that the physician-patient relationship is unique and hallowed. I would also recommend the article (3) Professions as the $\tilde{N}$ Conscience of Society by Paul Sieghart in the $\underset{\omega}{ }$ September 1985 issue of the fournal of Medical Ethics about physicians' responsibilities. I believe physicians 0 should set an example by their willingness to forego $\mathbb{C}$ personal benefit where the welfare of their patients is $\stackrel{\odot}{+}$ threatened. They certainly can afford to do this. They can and should take leadership in exploring $\frac{\vec{P}}{D}$

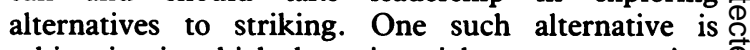
arbitration in which the union picks a representative, $\stackrel{\mathbb{Q}}{\varrho}$ the management another and the two arbitrators pick a $\overline{0}$ third, and where both sides agree in advance to abide by the ruling of the arbitrators. I believe this is but one $\frac{0}{0}$ of numerous possibilities that an educated and sophisticated group of professionals can explore and $\frac{0}{\bar{P}}$ 
experiment with as an alternative to the horrors of a health professionals' strike.

I believe physicians' strikes are unethical regardless of the provocation. I feel likewise about other employees whose failure to carry on their commitment would endanger human lives. If airline pilots threatened to parachute from their planes and leave their passengers without a pilot in mid-air that too is not acceptable. So too would be a strike of firemen or of employees in other vital services.

In a society where strikes in general are permitted, the exclusion of certain groups such as health workers and firemen from having the right to strike obligates the society in turn to provide them with an alternative means of achieving fair salary and working conditions.

With respect to politicians and others whose policies endanger human lives whether by design, incompetence or whatever, they too may obviously be acting unethically and should be held accountable for their failure. But their improprieties cannot be used as justification for similarly improper acts by other groups. Nor does the fact that they may be guilty of causing suffering and death render less valid their request (even if hypocritical) that health workers refrain from striking. One need not be a professional philosopher to know that two wrongs do not make one right.

In closing - I do not know Dr Brecher, nor the reason for the intemperateness of his attack, more in the style of Hyde Park than of a scholarly journal. I venture as one hypothesis that $\mathrm{Dr}$ Brecher is expressing the anger and self-righteousness that all too often characterises the New Left. I did not attempt to address the plethora of derogatory remarks in his reply (I counted at least 25 such phrases and adjectives). Nor did I attempt to apologise for such misdeeds as the failure to revise Robert Louis Stevenson's sexism. I trust that the readers will understand that my forbearance does not reflect my inability to answer each charge, but rather my unwillingness to descend to that level of argument. I believe that most of the substantive points raised by Brecher have been addressed. A number of broader philosophical issues including basic weltanschaung, definitions of democracy, ethics and ideal society, on which Brecher and I obviously differ widely, are far too broad to be handled in this short reply.

Professor Seymour M Glick MD is Head of the KupatHolim Department of Internal Medicine C, Soroka Medical Center, Beer-Sheba, Israel, (POB 151) and also Gussie Krupp Professor of Medicine at the Ben Gurion University of the Negev Faculty of Health Sciences.

\section{References}

(1) Kass L R. Professing ethically. Foumal of the American Medical Association 1982; 249: 1305-1310.

(2) Pellegrino E D. Humanism and the physican.Knoxville: University of Tennessee press, 1979.

(3) Sieghart P. Professions as the conscience of society. Fournal of medical ethics 1985; 11: 117-122. 